Harvard Data Science Review • Issue 4.1, Winter 2022

\title{
Finding Love on a First Data: Matching Algorithms in Online Dating
}

\section{Liesel L. Sharabi ${ }^{1}$}

${ }^{1_{H}}$ ugh Downs School of Human Communication, Arizona State University, Tempe, Arizona, United States of America

Published on: Jan 27, 2022

DOI: https://doi.org/10.1162/99608f92.1b5c3b7b

License: Creative Commons Attribution 4.0 International License (CC-BY 4.0). 
Column Editor's Note: Dating apps and online matchmaking are now a commonplace way for couples to meet and relationships to form. As human communications expert Liesel Sharabi explains, the algorithms underlying the matchmaking have evolved enormously in complexity over recent years, and our relationship with online dating apps have become a long-term prospect.

Keywords: algorithms, machine learning, matchmaking, online dating, recommender systems

Online dating has become the most common way for couples to meet in the United States (Rosenfeld et al., 2019). Fifty-two percent of Americans who have never been married say they have tried their luck with online dating (Anderson et al., 2020). There is also evidence that online dating may be changing the composition of real-world relationships. According to a 2013 study by Cacioppo et al., one-third of marriages in the United States are between partners who were introduced to each other online. Outside of the United States, millions of people use online dating services (Maybin et al., 2016).

Online dating generally progresses through a series of stages that involve filling out a profile, matching, messaging, and, if all goes well, meeting in person. Although success can mean different things depending on the person, meeting face-to-face (be it for casual sex or for a committed relationship) is generally a good indicator that a platform has done its job (Ellison et al., 2006). The problem for data science is finding the best way to filter and sort at the matching stage in order to make recommendations that will lead to successful outcomes. Most online dating platforms do this by relying on algorithms and artificial intelligence (AI) to introduce users to partners with whom they might be compatible. But can matching algorithms learn to predict what has long eluded their human creators: the secret to romantic compatibility? The following sections explore this question by tracing the history of online dating from desktop computers to smartphones and the emergence of modern methods for finding romance with data.

\section{Compatibility Matching on Online Dating Sites}

"The theoretical perspective underlying the online matchmaking paradigm is that who you are and who you choose to be with will have an enormous impact on the quality of your marriage." -Steven Carter and Galen Buckwalter, eHarmony 1

One of the first commercial forays into computerized dating took place at Harvard University in 1965 (Mathews, 1965), but it would be decades before online dating would go mainstream with the arrival of Match in the mid-1990s. Early online dating sites bore a strong resemblance to newspaper personal ads and were designed for users to click through profiles until they found someone who piqued their interest. The appeal of these sites was that they afforded greater access to potential partners, yet too many options can be overwhelming and leave people feeling dissatisfied with their decisions (Finkel et al., 2012; Schwartz, 2004). In a classic example of choice overload, Iyengar and Lepper (2000) presented grocery store shoppers with a 
tasting booth containing either six or 24 flavors of gourmet jam. Despite being drawn to the booth with more options, shoppers were the most likely to make a purchase when given fewer choices. Likewise, when online daters are given more profiles to examine, they are known to spend more time searching, to be less selective by considering options that do not meet their preferences, and to make poorer choices that do not fit what they are looking for in a partner (Wu \& Chiou, 2009).

Online dating sites began to experiment with compatibility matching in the early 2000s as a way to address the issue of choice overload by narrowing the dating pool. Matching algorithms also allowed sites to accomplish other goals, such as being able to charge higher fees for their services and enhancing user engagement and satisfaction (Jung et al., 2021; Sprecher, 2011). Since these algorithms did not have to work perfectly to be profitable (Sharabi \& Timmermans, 2021), there was flexibility in how they made their recommendations. The sites that rose to popularity around this time claimed to provide 'scientific matching' and relied on lengthy questionnaires to gather data about their users' preferences (Sprecher, 2011). Some sites even went so far as to eliminate the ability to search entirely, which meant that users had fewer options but also less competition since there were not as many profiles to choose from (Halaburda et al., 2018). Although much of the industry takes a black-box approach to algorithms (Courtois \& Timmermans, 2018), eHarmony and OkCupid have been a few of the more transparent sites in their approach to matchmaking.

In 2000, eHarmony was among the first online dating sites to develop and patent a matching algorithm for pairing users with compatible partners. The eHarmony algorithm was created by a team of psychologists led by the company's founder, Dr. Neil Clark Warren, and guided by research they conducted with 5,000 married couples (Tierney, 2008). Their intention was to lower the divorce rate by applying insights from marriage to intervene in the mating decisions of the site's single users (Slater, 2013). The original eHarmony algorithm was relatively simple by today's standards and used a regression-based approach to match users on variables believed to predict long-term relationship satisfaction (Buckwalter et al., 2004, 2008). As part of the sign-up process, users completed a compatibility test that included as many as 450 questions about themselves and their preferences for an ideal partner (eHarmony, 2021). In one of the few published tests of eHarmony's matchmaking paradigm, couples who matched on the site had higher quality marriages than those who were introduced via 'unfettered choice' (Carter \& Buckwalter, 2009, p. 105). Of course, this does not eliminate the possibility that, algorithm aside, the eHarmony couples may have been more motivated for their relationships to succeed in the first place (Houran et al., 2004).

Not long after, in 2004, OkCupid began offering algorithmic matching alongside the basic search functionality that users had come to expect from earlier sites. The combination of searching and matching on OkCupid meant the algorithm functioned as more of a decision aid by empowering users to seek out potential partners for themselves while also offering suggestions to narrow the field (Tong et al., 2016). OkCupid's algorithm used "match percentages" to assess compatibility based on how users answered questions and how they wanted potential partners to answer, and then it weighted each question by its reported level of importance (i.e., 
“irrelevant,” "a little,” "somewhat,” "very”; Rudder, 2013). The data came from an assortment of questions (e.g., “Are you afraid of death?” "Would you date someone who keeps a gun in the house?”), including those unlikely to be found on a scientific questionnaire (e.g., "Do you believe in dinosaurs?” "Is astrological sign at all important in a match?”; Cooper, 2017). By assuming the answers to some questions were more important than others, OkCupid gave users control over the matching process and the ability to provide input into how their data were used by the site's algorithm.

The problem with these early matching systems is that they assumed users knew precisely what they desired in a partner. However, people's stated preferences for an ideal mate do not always align with what they find attractive in person (Eastwick \& Finkel, 2008). This is further complicated by the fact that online dating often encourages users to prioritize qualities (e.g., height, income) that are poor indicators of what it will be like to interact with someone in the flesh (Frost et al., 2008). Many online dating sites have since started using more sophisticated machine learning algorithms to predict users' preferences from implicit forms of feedback (Dinh et al., 2021).

\section{Dating Apps and Collaborative Filtering}

"It's scary to know how much it'll affect people. I try to ignore some of it, or I'll go insane. We're getting to the point where we have a social responsibility to the world because we have this power to

$$
\begin{gathered}
\text { influence it." } \\
\text {-Jonathan Badeen, Tinder² }
\end{gathered}
$$

The release of the iPhone in 2007 and subsequent launch of Grindr in 2009 marked a seismic shift in the industry from online dating sites to mobile dating apps. Unlike their predecessors, dating apps required a quick sign-up process, prompting developers to turn to collaborative filtering to gain insight into their users'

preferences. Collaborative filtering algorithms work by delivering recommendations based on the behaviors of users who appear to have similar tastes (Krzywicki et al., 2015). For example, imagine a hypothetical scenario where Tyrone is attracted to Carlos. If others who like Carlos also show an interest in Zach, then Zach will be presented to Tyrone as a possible match. This strategy is used to suggest products on Amazon and movies on Netflix, but on dating apps, recommendations must be reciprocal to minimize rejection (Pizzato et al., 2013). In other words, matching algorithms must consider not only whether one person is likely to find another attractive but also whether that interest will be well received. Collaborative filtering is commonly used for matching on popular dating apps such as Tinder and Hinge (Lau \& Akkaraju, 2019).

Launched in 2012, Tinder is known for its gamified approach to dating and its emphasis on hookups and casual relationships, although it is no longer just a 'hookup app.' The Tinder app is designed to mirror a deck of playing cards where users can swipe left to "keep playing” and right to match, with a double opt-in system used to confirm both partners are interested before they can begin messaging (Myles, 2020). Like other games of skill, Tinder uses the Elo system (Elo, 1978) to rate the desirability of users and match them with others who 
are in roughly the same league (Carr, 2016). The Elo system comes from chess, where it is used to assign players a score based on their prior wins/losses and the skill levels of their opponents (Glickman, 1995). On Tinder, ratings work similarly, with a right swipe from someone desirable having the greatest impact on a user's score, just as a win against a Grandmaster in chess would matter more than beating an amateur player (Bartlett, 2020). Tinder claims to have retired Elo scores but provides few details about its new system (Tinder, 2019).

Also in 2012, Hinge was founded as a dating app geared toward long-term relationships. At Hinge, the GaleShapley algorithm (Gale \& Shapley, 1962) is used to recommend compatible matches to users (Carman, 2018). The Gale-Shapley algorithm solves the problem of creating stable matches between two groups when both sides prefer some partners over others (e.g., in the case of college admissions, marriage). Matches are stable if there are no two people who would rather be with each other than the partner they have been recommended (Gale \& Shapley, 1962). For instance, by matching Ravi with Ava, one can be confident that there is no one else in the dating pool they would prefer who would also be interested in them in return. Lloyd Shapley and Alvin Roth won the 2012 Nobel Memorial Prize in Economic Science for their work with the Gale-Shapley algorithm, which is in many ways a natural fit for online dating. However, this approach assumes that compatibility comes from matching people who are similar in desirability, when online daters are also known to engage in aspirational mate pursuit by seeking out the most desirable partners (Bruch \& Newman, 2018; Dinh et al., 2021).

One concern about the use of collaborative filtering for matchmaking is the potential for gender and racial bias to creep into the algorithms (Hutson et al., 2018; Zhang \& Yasseri, 2016). MonsterMatch (2019) is a dating app simulation that illustrates how this might happen and the ways collaborative filtering algorithms can exclude certain groups of users by privileging the behaviors of the majority. Rather than making dating more inclusive as was once hoped (Ortega \& Hergovich, 2018), the move to collaborative filtering may be reproducing many of the same biases seen offline (Nader, 2020). Given these concerns, MonsterMatch co-creator Ben Berman has urged dating app developers to provide users with the option to reset the algorithm by deleting their swipe history or to opt out of algorithmic matching entirely (Pardes, 2019). New techniques are also being developed to improve these algorithms by incorporating more diversity into their recommendations (Adomavicius \& Kwon, 2012; Chen et al., 2020).

\section{Relationship Outcomes: Is It All Placebo AI?}

"In the back of our minds, there's always been the possibility: maybe it works just because we tell people it does." -Christian Rudder, OkCupid $\underline{3}$

Now for the question on everyone's mind: Do the algorithms work? It can be difficult to say with any certainty since most matching algorithms are proprietary, but scientists are skeptical of their ability to predict long-term 
relationship success (Finkel et al., 2012). In a 2017 study, Joel et al. built a machine learning algorithm to attempt to predict romantic desire using constructs from relationship science. Although the algorithm provided some indication of a person's selectivity and desirability, it was unable to anticipate which people would hit it off in person. As Finkel et al. (2012) noted in regard to online dating, the forces behind compatibility are complicated and based on more than just the individual qualities that each partner brings to the relationship.

One thing that is becoming clear is that matching algorithms may not need to work for online dating to be effective. Sharabi (2021) uncovered a placebo effect in online dating, where people's positive expectations for compatibility matching predicted better first dates regardless of how well the algorithms actually worked.

OkCupid's user testing has similarly shown that placebo AI may be complicating developers' efforts to create a reliable matching system. In a blog post for OkTrends, Rudder (2014) described a series of experiments where bad matches were led to believe that they were good and good matches were lied to and told that they were not compatible (i.e., 30\% matches were increased to $90 \%$, and $90 \%$ matches were lowered to 30\%). While there were signs that OkCupid's algorithm worked, so too did merely suggesting someone was a compatible match.

\section{Conclusion}

Matching algorithms have come a long way from the online dating sites of the early 2000s to the dating apps of today and continue to grow increasingly complex. Looking to the future, a report by eHarmony projects that the next few decades could see algorithms integrated with DNA data and the Internet of Things in order to deliver more personalized recommendations (Deli et al., 2015). The developers at Hinge are also exploring ways that geolocation data can be used to optimize their algorithm with information about users' offline dates (LaPoff et al., 2021). Beyond matchmaking, algorithms will be key to creating safer and more equitable online dating experiences. For example, Bumble, which has been labeled a feminist dating app thanks to innovative design features that challenge pre-existing gender norms, has begun using AI to respond to harassment directed at women on the platform (Bumble, 2021). These advances make it important to consider how algorithms could affect the long journey of evolution of online dating by bringing about major changes in the coming years.

\section{Disclosure Statement}

Liesel L. Sharabi has no financial or non-financial disclosures to share for this article.

\section{References}

Adomavicius, G., \& Kwon, Y. (2012). Improving aggregate recommendation diversity using ranking-based techniques. IEEE Transactions on Knowledge and Data Engineering, 24(5), 896-911.

https://doi.org/10.1109/TKDE.2011.15 
Anderson, M., Vogels, E. A., \& Turner, E. (2020, February 6). The virtues and downsides of online dating. Pew Research Center. https://www.pewresearch.org/internet/2020/02/06/the-virtues-and-downsides-of-online-dating/

Bartlett, M. (2020, July 17). How Tinder’s algorithm micromanages your dating life. Technocracy. https://technocracy.substack.com/p/how-tinders-algorithm-micromanages

Bowles, N. (2016, January 11). Mr. (swipe) right? The California Sunday Magazine. https://story.californiasunday.com/sean-rad-tinder/

Bruch, E. E., \& Newman, M. E. J. (2018). Aspirational pursuit of mates in online dating markets. Science Advances, 4(8). https://doi.org/10.1126/sciadv.aap 9815

Buckwalter, J. G., Carter, S. R., Forgatch, G. T., Parsons, T. D., \& Warren, N. C. (2004). Method and system for identifying people who are likely to have a successful relationship. U.S. Patent No. 6,735,568 B1. U.S. Patent and Trademark Office.

Buckwalter, J. G., Carter, S. R., Forgatch, G. T., Parsons, T. D., \& Warren, N. C. (2008). Method and system for identifying people who are likely to have a successful relationship. U.S. Patent No. 7,454,357 B2. U.S. Patent and Trademark Office.

Bumble. (2021). With Bumble's private detector, you have control over unsolicited nudes. https://bumble.com/en-us/the-buzz/privatedetector

Cacioppo, J. T., Cacioppo, S., Gonzaga, G. C., Ogburn, E. L., \& VanderWeele, T. J. (2013). Marital satisfaction and break-ups differ across on-line and off-line meeting venues. Proceedings of the National Academy of Sciences, 110(25), 10135-10140. https://doi.org/10.1073/pnas.1222447110

Carman, A. (2018, July 11). Hinge’s newest feature claims to use machine learning to find your best match. The Verge. https://www.theverge.com/2018/7/11/17560352/hinge-most-compatible-dating-machine-learningmatch-recommendation

Carr, A. (2016, January 11). I found out my secret internal Tinder rating and now I wish I hadn't. Fast Company. https://www.fastcompany.com/3054871/whats-your-tinder-score-inside-the-apps-internal-ranking= system

Carter, S. R., \& Buckwalter, J. G. (2009). Enhancing mate selection through the Internet: A comparison of relationship quality between marriages arising from an online matchmaking system and marriages arising from unfettered selection. Interpersona: An International Journal on Personal Relationships, 3(2), 105-125. https://doi.org/10.5964/ijpr.v3isupp2.78 
Chen, J., Dong, H., Wang, X., Feng, F., Wang, M., \& He, X. (2020). Bias and debias in recommender system: A survey and future directions. arXiv. https://doi.org/10.48550/arXiv.2010.03240

Cooper, K. (2017, October 15). The most important questions on OkCupid. The OkCupid Blog. https://theblog.okcupid.com/the-most-important-questions-on-okcupid-32e80bad0854

Courtois, C., \& Timmermans, E. (2018). Cracking the Tinder code: An experience sampling approach to the dynamics and impact of platform governing algorithms. Journal of Computer-Mediated Communication, 23(4), 1-16. https://doi.org/10.1093/jcmc/zmx001

Deli, E., Depotter, C., Lewis, N., Nam, K. M., Silfanus, N., Voirin, N., \& Ng, W. W. (2015). The future of dating: 2040. eHarmony UK and Imperial College Business School. https://www.eharmony.co.uk/wordpress/wp-content/uploads/sites/3/2021/04/eHarmony.co .uk-ImperialCollege-Future-of-Dating-Report-20401.pdf

Dinh, R., Gildersleve, P., Blex, C., \& Yasseri, T. (2021). Computational courtship understanding the evolution of online dating through large-scale data analysis. Journal of Computational Social Science. https://doi.org/10.1007/s42001-021-00132-w

Eastwick, P. W., \& Finkel, E. J. (2008). Sex differences in mate preferences revisited: Do people know what they initially desire in a romantic partner? Journal of Personality and Social Psychology, 94(2), 245-264. https://doi.org/10.1037/0022-3514.94.2.245

eHarmony. (2021). The history of online dating. https://www.eharmony.com/history-of-online-dating/

Ellison, N., Heino, R., \& Gibbs, J. (2006). Managing impressions online: Self-presentation processes in the online dating environment. Journal of Computer-Mediated Communication, 11(2), 415-441. https://doi.org/10.1111/j.1083-6101.2006.00020.x

Elo, A. E. (1978). The rating of chessplayers, past and present. Arco Publishing.

Finkel, E. J., Eastwick, P. W., Karney, B. R., Reis, H. T., \& Sprecher, S. (2012). Online dating: A critical analysis from the perspective of psychological science. Psychological Science in the Public Interest, 13(1), 366. https://doi.org/10.1177/1529100612436522

Frost, J. H., Chance, Z., Norton, M. I., \& Ariely, D. (2008). People are experience goods: Improving online dating with virtual dates. Journal of Interactive Marketing, 22(1), 51-61. https://doi.org/10.1002/dir.20107 Gale, D., \& Shapley, L. S. (1962). College admissions and the stability of marriage. The American Mathematical Monthly, 69(1), 9-15. https://doi.org/10.2307.2312726

Glickman, M. E. (1995). A comprehensive guide to chess ratings. American Chess Journal, 3, 59-102. 
Halaburda, H., Piskorski, M. J., \& Yildirim, P. (2018). Competing by restricting choice: The case of matching platforms. Management Science, 64(8), 3574-3594. https://doi.org/10.1287/mnsc.2017.2797

Houran, J., Lange, R., Rentfrow, P. J., \& Bruckner, K. H. (2004). Do online matchmaking tests work? An assessment of preliminary evidence for a publicized "predictive model of marital success." North American Journal of Psychology, 6(3), 507-526.

Hutson, J., Taft, J. G., Barocas, S., \& Levy, K. (2018). Debiasing desire: Addressing bias \& discrimination on intimate platforms. Proceedings of the ACM on Human-Computer Interaction, 2(CSCW), Article 73. https://doi.org/10.1145/3274342

Iyengar, S. S., \& Lepper, M. R. (2000). When choice is demotivating: Can one desire too much of a good thing? Journal of Personality and Social Psychology, 79(6), 995-1006. https://doi.org/10.1037//0022$\underline{3514.79 .6 .995}$

Joel, S., Eastwick, P. W., \& Finkel, E. J. (2017). Is romantic desire predictable? Machine learning applied to initial romantic attraction. Psychological Science, 28(10), 1478-1489.

https://doi.org/10.1177/0956797617714580

Jung, J., Lim, H., Lee, D., \& Kim, C. (2021). The secret to finding a match: A field experiment on choice capacity design in an online dating platform. Information Systems Research, Ahead of Print. https://doi.org/10.1287/isre.2021.1028

Krzywicki, A., Wobcke, W., Kim, Y. S., Cai, X., Bain, M., Mahidadia, A., \& Compton, P. (2015).

Collaborative filtering for people-to-people recommendation in online dating: Data analysis and user trial. International Journal of Human-Computer Studies, 76, 50-66. https://doi.org/10.1016/j.ijhcs.2014.12.003

LaPoff, M., Chesbrough, J., Mort, L., Levy, S., MacGougan, T., McGrath, J. M., \& McLeod, J. (2021). System and method for providing enhanced recommendations based on ratings of offline experiences. U.S. Patent Application No. 2021/0109938 A1. U.S. Patent and Trademark Office.

Lau, T., \& Akkaraju, U. (2019, November 12). When algorithms decide whose voices will be heard. Harvard Business Review. https://hbr.org/2019/11/when-algorithms-decide-whose-voice-will-be-heard

Mathews, T. J. (1965, November 3). Operation Match. The Harvard Crimson. https://www.thecrimson.com/article/1965/11/3/operation-match-pif-you-stop-to/

Maybin, S., Maguire, E., Price, H. C., Walton, J., \& Shah, P. (2016, February 12). The dating game: Which dating apps are winning the hearts of the world? BBC News. https://www.bbc.co.uk/news/resources/idt2e3f0042-75f6-4bd1-b4fe-9056540c65f8 
MonsterMatch. (2019). Dating app algorithms: Learn how the algorithms figure you out in a dating app. https://monstermatch.hiddenswitch.com/algorithms

Myles, D. (2020). Romantic and sexual encounters in the age of algorithms: A comparative analysis of Grindr and Tinder. In C. Piazzesi, M. Blais, J. Lavigne, \& C. Lavoie Mongrain (Eds.), Contemporary intimacies and sexualities: Social changes, transformations in practices, and representations (pp. 1-11). Montreal Press.

Nader, K. (2020). Dating through the filters. Social Philosophy and Policy, 37(2), 237-248.

https://doi.org/10.1017/S0265052521000133

Ortega, J., \& Hergovich, P. (2018). The strength of absent ties: Social integration via online dating. arXiv. https://doi.org/10.48550/arXiv.1709.10478

Pardes, A. (2019, May 25). This dating app exposes the monstrous bias of algorithms. Wired. https://www.wired.com/story/monster-match-dating-äpp/

Pizzato, L., Rej, T., Akehurst, J., Koprinska, I., Yacef, K., \& Kay, J. (2013). Recommending people to people: The nature of reciprocal recommenders with a case study in online dating. User Modeling and User-Adapted Interaction, 23(5), 447-488. https://doi.org/10.1007/s11257-012-9125-0

Rosenfeld, M. J., Thomas, R. J., \& Hausen, S. (2019). Disintermediating your friends: How online dating in the United States displaces other ways of meeting. Proceedings of the National Academy of Sciences of the United States of America, 116(36), 17753-17758. https://doi.org/10.1073/pnas.1908630116

Rudder, C. (2013, February). Inside OkCupid: The math of online dating [Video]. TED Conferences. https://www.ted.com/talks/christian rudder inside okcupid the math of online dating?language $=$ en

Rudder, C. (2014, July 28). We experiment on human beings! OkTrends. https://www.gwern.net/docs/psychology/okcupid/weexperimentonhumanbeings.html

Schwartz, B. (2004). The paradox of choice: Why more is less. HarperCollins.

Sharabi, L. L. (2021). Exploring how beliefs about algorithms shape (offline) success in online dating: A twowave longitudinal investigation. Communication Research, 48(7), 931-952.

https://doi.org/10.1177/0093650219896936

Sharabi, L. L., \& Timmermans, E. (2021). Why settle when there are plenty of fish in the sea? Rusbult's investment model applied to online dating. New Media \& Society, 23(10), 2926-2946.

https://doi.org/10.1177/1461444820937660

Slater, D. (2013). Love in the time of algorithms: What technology does to meeting and mating. Penguin. 
Sprecher, S. (2011). Relationship compatibility, compatible matches, and compatibility matching.

Psychological Research Records, 1(2), 187-215. https://doi.org/10.22201/fpsi.20074719e.2011.2.203

Tierney, J. (2008, January 29). Hitting it off, thanks to algorithms of love. The New York Times.

https://www.nytimes.com/2008/01/29/science/29tier.html

Tinder. (2019, March 15). Powering Tinder-The method behind our matching.

https://blog:gotinder.com/powering-tinder-r-the-method-behind-our-matching/

Tong, S. T., Hancock, J. T., \& Slatcher, R. B. (2016). Online dating system design and relational decision making: Choice, algorithms, and control. Personal Relationships, 23(4), 645-662.

https://doi.org/10.1111/pere.12158

Wu, P. L., \& Chiou, W. B. (2009). More options lead to more searching and worse choices in finding partners for romantic relationships online: An experimental study. CyberPsychology \& Behavior, 12(3), 315-318. https://doi.org/10.1089/cpb.2008.0182

Zhang, J., \& Yasseri, T. (2016). What happens after you both swipe right: A statistical description of mobile dating communications. arXiv. https://doi.org/10.48550/arXiv.1607.03320

(C2022 Liesel L. Sharabi. This article is licensed under a Creative Commons Attribution (CC BY 4.0) International license, except where otherwise indicated with respect to particular material included in the article.

\section{Footnotes}

1. Carter and Buckwalter (2009, p. 106).

2. Bowles (2016) as cited in Bartlett (2020, para. 14).

3. Rudder (2014, para. 20). 